\title{
The Role of Prior Mathematical Experience in Predicting Mathematics Performance in Higher Education
}

\author{
Fiona Faulkner \\ Technological University Dublin, fiona.faulkner@tudublin.ie \\ Ailish Hannigan \\ Olivia Fitzmaurice
}

Follow this and additional works at: https://arrow.tudublin.ie/ltcart

Part of the Education Commons

\section{Recommended Citation}

Faulkner, F., Hannigan, A. \& Fitzmaurice, A. (2014). The role of prior mathematical experience in predicting mathematics performance in high education. International Journal of Mathematical Education in Science and Technology, vol. 45, no. 5. doi.org/10.1080/0020739X.2013.868539

This Article is brought to you for free and open access by the Learning Teaching \& Assessment at ARROW@TU Dublin. It has been accepted for inclusion in Articles by an authorized administrator of ARROW@TU Dublin. For more information, please contact arrow.admin@tudublin.ie, aisling.coyne@tudublin.ie, gerard.connolly@tudublin.ie.

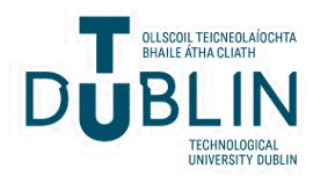




\section{The Role of Prior Mathematical Experience in Predicting Mathematics Performance in Higher Education}

Evidence of deficiencies in basic mathematical skills of beginning undergraduates has been documented worldwide. Many different theories have been set out as to why these declines in mathematical competency levels have occurred over time. One such theory is the widening access to higher education which has resulted in a less mathematically prepared profile of beginning undergraduates than ever before. In response to this situation, the present study details the examination of a range of methods through which a student's mathematical performance in higher education could be predicted at the beginning of their third level studies. Several statistical prediction methods were examined and the most effective method in predicting students' mathematical performance was discriminant analysis. The discriminant analysis correctly classified $71.3 \%$ of students in terms of mathematics performance. An ability to carry out such a prediction in turn allows for appropriate mathematics remediation to be offered to students predicted to fail third level mathematics. The results of the prediction of mathematical performance, which was carried out using a database consisting of over 1,000 beginning undergraduates over a three year period, are detailed in this article along with the implications of such findings to educational policy and practice.

Keywords: Predicting performance, mathematics problem, declining standards, changing profile, widening access, remediation.

\section{Introduction}

It has often been said that the economic success of any country is dependent upon the knowledge and skills of the individuals within it [1]. A 'knowledge economy' can be built through the development and distribution of well educated individuals, with particular emphasis on scientists, engineers and technologists, into the working world [2]. These disciplines, on which a strong economy is so heavily dependent, are strongly 
reliant on mathematics and so the title given to the decline in standards on entry to higher education is quite fitting; 'The Mathematics Problem'. The main concerns of this problem, which were first reported in the UK, relate to a steady decline of fluency in basic mathematical skills and the under-preparedness of students entering higher education to cope with the mathematical demands made on them [3].

Internationally (e.g. Australia, USA, UK, Ireland) ‘under-prepared’ students demonstrate some or all of the following characteristics[4]:

- $\quad$ Large gaps in mathematical knowledge.

- Numeracy skills which are inadequate to cope with everyday mathematical skills.

- Poor competency levels in algebraic manipulation and simplification.

- Difficulty when applying mathematics, particularly when met in unfamiliar formats.

- Lack of ability to reason mathematically.

Concerns regarding the 'Mathematics Problem' have been reported internationally [56]. In Australia, reports have been made over the last decade detailing concerns about the fact that declining mathematics standards are negatively affecting the industry sector [7]. The "never ending downward spiral" of mathematics education has been written about in Queensland [5]. This study was motivated by the notable decline of students' first year academic performance in mathematics over a ten-year period.

The 'Mathematics Problem' has also been highlighted in the United States. The National Science Foundation (NSF) called for a funding boost in 2000 in order to reverse the decline in mathematics standards and make mathematics a more attractive profession [8]. At one stage, over half of all entering freshman in California were underprepared for college-level mathematics despite the California State University 
system's policy of accepting only students from the upper half of their graduating class [9]. Research carried out in the US over two decades ago highlighted the declining standards of basic mathematical skills of students entering undergraduate programmes involving mathematics [10].

In a Canadian study the knowledge and skills of incoming university students were described as being "far from satisfactory” (p.149) when transitional issues from mathematics in second level education to mathematics in higher education were being discussed in McMaster University [11].

In the UK in 1995 a report entitled “Tackling the Mathematics Problem” was published by the London Mathematical Society, the Institute of Mathematics and its Applications, and the Royal Statistical Society as a response to each party’s concerns regarding the mathematical preparedness of new undergraduates [12]. This issue was acknowledged again in the UK: “....the United Kingdom faces extremely serious problems to the supply and the mathematical preparation of entrants to university courses" [13]. These issues are re-addressed in another report entitled "Measuring the Mathematics Problem” by the Engineering Council in 2000 who again acknowledged the serious decline in students' fundamental mathematics skills and consequently their preparedness for mathematics in higher education. In the UK the fallen standards in mathematics over the last two decades have been partially blamed on the mathematics curriculum in second level education maintaining that it does not adequately prepare students for higher education [14]. Much of the research carried out in the UK calls for a system to be put in place in an attempt to remedy the issue of declining mathematical standards [15-16].

Research surrounding the 'Mathematics Problem' and related issues in Ireland have become more widespread in recent times $[4,17]$. Similar to much of the 
international research in this area, Irish students who enter higher education and have a poor grasp of basic mathematical concepts are categorised as ‘under-prepared' for mathematics in higher education or 'at risk' of failing mathematics in higher education [18].

Several studies have found a statistically significant association between mathematical attainment in the first year of post-secondary education and drop-out in higher education [19-20]. The potential detrimental effects which the 'Mathematics Problem' could have on retention rates in higher education is therefore cause for concern. Additionally, juxtaposing the poor mathematical performance of beginning undergraduate students with the skills necessary to function in today’s workplace (i.e. problem solving and skill application) highlights the seriousness of the mathematical shortcomings among beginning undergraduate students worldwide.

\subsection{Widening Access to Higher Education and the Changing Student Profile}

Widening access to higher education has led to a changing student profile in many countries such as the UK [21] Australia [22], the U.S and many parts of Europe [23]. Similarly the profile of students entering higher education in Ireland has changed considerably between 1998 and 2008 [24]. The proportion of students entering higher education in Ireland from secondary school has been increasing steadily over the last 20 years, from $20 \%$ in 1980 to $54 \%$ in 2003 to almost 66\% in 2010 [20]. Thirty years ago the vast majority of students entering higher level education in Ireland came directly from secondary school, however today higher education can be accessed from several different routes such as recognition of formal and informal prior learning, access courses for underrepresented groups, mature students and international students. 
Improving access to higher education among those in lower socio-economic groups has been a government priority in Ireland in recent times [25]. The most recent strategy which attempted to achieve equality of access to higher education in Ireland was focused on the years 2005-2007. This action plan had several goals, one of them being increased routes of access and progression to higher education [26]. It was reported to have been a successful initiative [25] as the numbers grew steadily. Widening access to higher education has proven to have many positive follow-on effects. In the U.S for example, a college graduate is more likely to have a better quality of life as a result of their education [27] and their spouses and children tend to be more educated also [28]. In addition to this a significant association has been found between a parent's level of graduate education and a student's attainment in second level education [29]. In a UK context the merits of widening participation in higher education have been documented on an on-going basis. Widening participation has been found to increase the provision of third level educational opportunities for students with disabilities, those in ethnic minority groups as well as female students [30]. In an Irish context widening access has been found to act as an informal 'first step' for many mature students, either by allowing them to 'test' the waters in third level education or by increasing their interest in progression [31]. Widening participation in higher education in Ireland has also been found to aid the development of a knowledge intensive workforce which is a primary source of competitive advantage for any country [32]. These outcomes are naturally desirable for a country's economic success and highlight the positive follow-on effects which aiding students to successfully complete their higher education studies can have [33].

Despite all of the positive aspects of the increased access to higher education in Ireland and elsewhere, this move must be and has been considered in light of the 
declining standards of the basic mathematical skills, as measured by diagnostic test data, of beginning undergraduates upon entry to higher education [34]. The international move towards a system of mass education, which now involves a large proportion of students who do not come directly from second level education, has resulted in the number and range of mathematical abilities of beginning undergraduates growing substantially over the years $[4,35]$. The widening of access to higher education has been found to be a contributing factor to the increased incidence of beginning undergraduates with lower prior academic attainment, including mathematics, than ever before [14, 24, 36]. It has also been found to be linked with declining student progression and retention rates [35]. The widening of access to higher education can therefore be seen as contributing to the decline in the mathematical preparedness of beginning undergraduates internationally $[14,24,36]$.

This phenomenon in higher education is not specific to Ireland but rather has been reported worldwide [37-38]. The investigations carried out in this article are therefore significant as it is no longer exclusively elite second level students who progress to higher education. It is therefore vital that we determine the mathematical preparedness of the recent cohorts of students entering higher education in order to be able to cater for their specific needs. Previously higher education institutions have put measures in place (such as diagnostic testing) in an attempt to identify students' likelihood of failing mathematics and in turn provided appropriate mathematics remediation. However few institutions have carried out such investigations in an objective evidence based manner. Such an investigation would allow one to not only predict students probable performance in mathematics in a binary manner (success/failure) but would also allow one to predict the extent to which a student is at risk of failing mathematics in a higher education institution. 
Many third level institutions have responded to the decline in mathematical standards of beginning undergraduates over time and the changing student profile by providing students with mathematics remediation.

\subsection{The Role of Post-Secondary Mathematics Remediation in Higher Education}

Many educationalists believe that the 'Maths Problem' is best tackled at its source i.e. in primary and secondary school. As a result of such a belief attempts have been made in several countries to improve teaching methodologies and mathematics curricula in second level education, for example in the UK and Ireland [3, 39]. Post-secondary mathematics remediation has therefore been known to divide educationalists [40]. Those who are not in favour of it maintain that it is a structure which requires the tax payer to pay twice for the same educational opportunities; first in secondary school and again in college [41-42]. Others are critical of it as they feel presenting second level material in higher institutions downgrades the academic standards of higher education institutions [43].

On the other hand those who are in support of post-secondary mathematics remediation have highlighted its function in supporting individuals who lack basic competencies in a fundamental subject [44] hence making effective functioning participation in society a possibility for all [45]. It has also been found to provide equality of education hence reducing the differences between the advantaged and disadvantaged [41]. Regardless of one's standpoint on post-secondary mathematics remediation it has been described as an essential part of higher education today as well as a necessity worldwide if degree standards are to be maintained [44-45]. A recent study involving 85,894 students found that students who were involved in remediation were indistinguishable from those who were not involved in it in terms of credential 
attainment and transfer, hence highlighting that mathematics remediation can and does work [40].

The continuing presence of the 'Mathematics Problem' in higher education and the consequential need for mathematics remediation motivated this study to predict performance in mathematics in university on the basis of information measured on entry to higher education. If one could predict the students who were likely to be 'at risk' of failing mathematics then students could be assigned an appropriate remediation programme in an attempt to prevent them from failing mathematics and to maintain degree standards.

\section{This Study: Background Information}

\subsection{The University of Limerick}

The University of Limerick is a higher education institution in Ireland with a primary focus on Science and Technology subjects. It currently has over 12,000 students and 1,400 staff members with 4 different faculties consisting of 25 departments. The largest faculty is the Science and Engineering faculty which consists of 10 different departments one of which is the Mathematics and Statistics department. The Department of Mathematics and Statistics deliver service mathematics modules to its client departments (Science, Technology, Business, Computers and Engineering). Service mathematics refers to mathematics offered to degree courses where mathematics is required, but is not the main focus of the degree. The research detailed in this paper focuses on two of the service mathematics groups: Science and Technology students. There has been a large increase in the numbers of students enrolling in degree programmes which are required to do Science and Technology 
mathematics. In 1998 there were 202 and 305 students enrolled in Science and Technology mathematics respectively which rose to 303 and 374 in 2008 . The increasing number of students within the Science and Technology cohorts has been due in part to the increased number of degree programmes on offer in UL; from 8 to 14 degree programmes in Technology mathematics and from 8 to 11 in Science mathematics [34]. Although many Science and Technology mathematics students are required to study mathematics beyond the first year of their degree programmes, this report focuses solely on their first year mathematics performance.

\subsection{Diagnostic Testing in $U L$}

In 1997 diagnostic testing was first implemented in UL due to service mathematics lecturers’ anxiety regarding Science and Technology students’ mathematical competency levels. The test is a tool to identify those who are struggling with the basic mathematical concepts needed for third level education. This information can then be used by lecturers to understand the ability of their students and for students to identify where their weaknesses may lie and if they need extra help [34].

There has been almost 8,000 students involved in diagnostic testing in UL to date. The diagnostic test is administered to students in the first lecture of first year service mathematics modules, Science and Technology mathematics. The students do not receive prior warning about the test, with the hope being that this approach increases the number of students taking the test. There are 40 questions on the diagnostic test. There have been no changes made to the diagnostic test, in content or structure, since it was first implemented in 1997 so comparisons across cohorts can be made. If students receive 19 out of 40 or below in the diagnostic test they are considered to be 'at risk' of failing service mathematics in UL. An 'at risk' student is regarded as someone who is 
deficient in the mathematical skills deemed necessary for successful completion of their mathematics module. The students who are categorised as 'at risk' are advised to avail of the mathematics remediation services made available to them by the university [18].

\subsection{The University of Limerick Database}

A global database was created which consists of all of the data from Science and Technology students from 1998-2008. This database contains almost 6,000 students

(see table 1). A sub-group of this data is used for the analysis detailed in this paper (see section 5 for more details).

For each student, there are over 60 items of information. The information detailed for each student is outlined in table 1. Information as to whether a student is considered standard or non-standard is outlined. A non-standard student is defined as a student who did not enter UL through the central application system used by all higher education institutions in Ireland. This cohort therefore consists of mature students (i.e. anyone over the age of 23 who has gained access to UL on the basis of an interview), non-national students and those who have completed previous certificate/diploma/degree and have used these as an entry point to UL. Details of students diagnostic test score total (out of 40), test profiles based on questions 1-40 (correct or incorrect/unanswered) and each student's performance in each topic on the diagnostic test is also detailed, i.e. arithmetic, algebra etc. (see table 1).

\section{[Insert Table 1 here]}

\subsubsection{Entry into Third Level Education in Ireland}

In Ireland second level education involves two programs: the Junior Certificate program, which takes three years to complete, and the Leaving Certificate program, 
which takes two years to complete. Students begin second level education at age 12-14 and finish at age 17-19 approximately. On completion of the Junior Certificate program students are equipped with the pre-requisite knowledge necessary for successful completion of the Leaving Certificate program. Both programs are completed through a summative state examination at the end of the three and two year periods respectively. Mathematics at Junior Certificate and Leaving Certificate can be taken at three levels; Higher Level, Ordinary Level and Foundation Level. Generally only students who have completed the Higher Level mathematics Junior Certificate examination take Higher Level mathematics for the Leaving Certificate. Direct entry to third level education in Ireland can be gained through students receiving sufficient Leaving Certificate grades at second level. The third level course which a student is eligible for is determined by a student's performance in all six subjects taken in the Leaving Certificate examination. Overall performance in this examination, which is the final state examination taken by second level students, is based on a points system. Typically students take seven subjects at Leaving Certificate, three of which must be mathematics, Irish and English, providing students do not have an exemption from them. Each grade received in the Leaving Certificate examination is awarded a specific number of points (see table 2). The total of a student's highest six grades is calculated to give their CAO (Central Applications Office) points. The maximum points which can be awarded is therefore 600 points.

[Insert Table 2 here]

\section{Research Questions to be Addressed and Research Hypothesis}

The research questions to be addressed are as follows: 
1. Can one predict who will fail first year mathematics in higher education using student information prior to the commencement of the academic term?

2. What are the best predictors of failure in first year mathematics in higher education?

3. Can the current method of determining whether a first year student is 'at risk' of failing mathematics in UL (i.e. the diagnostic test) be improved upon?

4. What effect if any does gender have on mathematics attainment in third level education?

The hypothesis within this research is that: There will be a means of predicting students' likelihood of failing first year mathematics in higher education and in turn an objective evidence based means of determining a student's probable mathematical performance will have been developed.

\section{Increase in 'at risk' Service Mathematics Students and the Changing Student Profile Over Time in UL}

Examination of the UL database in previous research revealed that the student profile in Science and Technology mathematics had changed greatly between 1998 and 2008 [24]. There was an increase of 9.1 and 5.4 percentage points of non- standard students in Technology and Science mathematics respectively. The increase in non-standard students was matched with a decrease in the percentage of students entering service mathematics in UL with Higher Level second level mathematics. A decrease of 7.8 percentage points occurred within the Technology cohort and a decrease of 17.4 percentage points occurred within the Science cohort. Higher Level mathematics in second level education in Ireland covers more topics at a more advanced level than the Ordinary Level mathematics course. For example Higher Level students are required to 
study integration while Ordinary Level students are not. The percentage of 'at risk' students has increased within both service mathematics cohorts from 32.8\% in 1998 to 46.4\% in 2008 for Technology mathematics students and from $21.3 \%$ to $46.0 \%$ for Science mathematics students. The changing profile of Science and Technological mathematics students between 1998 and 2008 was found to be a major contributing factor to the declining standards in mathematical competency as measured by the UL diagnostic test of students entering UL [24].

\section{Prediction of Student Failure in Service Mathematics}

The current method for determining whether a student may be 'at risk' of failing service mathematics in UL is the diagnostic test. Several statistical methods for predicting performance have been explored within this research study to identify those students most likely to fail first semester mathematics. It was also hoped that a new statistical prediction method could also be used as a tool to inform policy and support on the changing student profile and declining mathematical standards over time. The database used for this examination was one which involved Technology mathematics students between 2006 and $2008(n=1080)$. The years 2006, 2007 and 2008 were chosen for this analysis as within this time period the lecturer of Technology mathematics remained the same. The student body has remained constant in terms of prior mathematical attainment during this time period (see table 3). Theses consistencies therefore allowed for an examination of three quite similar conditions enabling a more powerful analysis of the characteristics which students possess that are associated with success in service mathematics and those which are associated with failure. The proportion of students who failed Technology mathematics in the 2006 cohort was $21.3 \%$, in 2007 it was $25.6 \%$ and in 2008 it was $23.5 \%$. 
Three different statistical prediction methods were used in this research;

Discriminant Analysis, Logistic Regression and Classification Trees. The method which correctly predicted the performance (pass/fail) of the highest proportion of students was considered to be the most successful. The statistical software package SPSS was used for all statistical analysis carried out within this research. Logistic regression can handle both qualitative and quantitative predictor variables. Classification trees have the advantage of also being able to predict using any data type (qualitative and quantitative) while also producing user friendly output. Discriminant analysis has the limitation of only being able to predict using quantitative predictor variables. In spite of this however discriminant analysis was found to be the most effective method of discriminating between those who passed and those who failed service mathematics of all three prediction methods. The logistic regression analysis correctly classified $39.0 \%$ of the unsuccessful students and the classification trees correctly classified $39.4 \%$ of the unsuccessful students. The discriminant analysis correctly classified $84.4 \%$ of unsuccessful students. The discriminant analysis therefore correctly classified $45.4 \%$ more unsuccessful students than the logistic regression and $45.0 \%$ more than the classification trees. The full results of the discriminant analysis are detailed in the following section.

\subsection{Discriminant Analysis Findings}

Discriminant analysis uses numeric variables to predict group membership. It can be carried out using one or more independent variables. Take for example the classification of first year undergraduate students as being either successful or unsuccessful in the first year of their degree programmes. The characteristics being used to classify the students is attendance at lectures (see figure 1). The distribution of attendance must be estimated 
from a representative group for each population, i.e. the spread of attendance of students who failed the first year of their degree programme from previous cohorts and the spread of attendance of those who were successful from previous cohorts. In this example low attendance would result in a student being classified as unsuccessful (i.e. being from population I) and high attendance would classify you as being successful (i.e. being from population II).

\section{[Insert figure 1 here]}

A dividing point $\mathrm{C}$ must be selected so that what is considered a high and low value of attendance can be decided upon. Providing equal variances can be assumed for each population, $\mathrm{C}$ is calculated as follows:

$$
\frac{\overline{X_{I}}+\overline{X_{I I}}}{2}
$$

The predictor variables used in logistic regression and classification tree analysis were as follows: gender, prior mathematical attainment, programme of study, non-standard student sub-category, whether a student sat the diagnostic test or not, performance in each individual section of the diagnostic test (i.e. algebra, arithmetic etc) and overall performance in the diagnostic test out of 40 . Both prediction methods found prior mathematical attainment to be a statistically significant predictor of performance in service mathematics with classification trees also finding diagnostic test result to be a statistically significant predictor. These analyses therefore determined that all other variables considered added no predictive ability. The effects of gender on mathematics attainment and consequently its strength as a predictor of service mathematics performance were found to be negligible. It had no statistically significant effect on the predictive ability of the logistic regression model $(\mathrm{p}=0.369)$ and was also not found to 
be statistically significant in the classification tree analysis and so did not determine any of the splits with the model ( $\mathrm{p}>0.05$ ). Discriminant analysis was carried out using the predictor variables diagnostic test results, prior mathematical attainment and performance in each individual topic on the diagnostic test (i.e. algebra, arithmetic sections etc.) as it can only deal with numeric variables. The only variables found to be statistically significant were diagnostic test results $(\mathrm{p}<0.05)$ and prior mathematical attainment ( $\mathrm{p}<0.001)$. The model could therefore only predict a student's probability of failure if data on both their diagnostic test results and prior mathematical attainment was detailed in the database. This eliminated non-standard students from much of the predictions as the majority of these students do not have/ cannot remember their prior mathematical attainment. It was expected that a more multi-dimensional model with more than two statistically significant predictor variables would have emerged when examining each of the prediction methods, however that was not the case for this database.

\subsection{The Discriminant Function}

When discriminant analysis was carried out in SPSS using the Technology 2006-2008 database the following Discriminant Function was obtained:

$Z=0.067$ (Prior Mathematical Attainment) +0.087 (Diagnostic Test Result), where $C=$ 5.078

If an individual in this dataset had a $Z$ value of $Z \geq 5.078$, the individual was classified as being successful and if $\mathrm{Z}<5.078$, the individual was classified as being unsuccessful. Along with being classified in this binary manner (i.e. successful/unsuccessful) a probability of failure was calculated for each student. The probability of failure was calculated using the following formula: 


$$
1-\frac{1}{1+\exp (-Z+C)}
$$

The relative importance of prior mathematical attainment was higher than any other potential predictor of performance of higher education mathematics measured in this study. The discriminant function correctly classified $68.2 \%$ of successful cases i.e. those who passed mathematics, $84.4 \%$ of unsuccessful cases i.e. those who failed mathematics and overall it correctly classified $71.3 \%$ of cases (see table 4 ). It is important that the function has a high percentage of correct classification of unsuccessful students as these are the students who need to be most aware of their probability of failure. The discriminant function was therefore quite successful in its prediction of service mathematics performance. The predictor variables, prior mathematical attainment and diagnostic test results, had the ability to explain some of the variability in service mathematics performance but not all.

\section{[Insert table 4 here]}

The discriminant function variables had standardised discriminant co-efficients of 0.857 for prior mathematical attainment and 0.512 for diagnostic test score. This highlighted that prior mathematical attainment had a larger relative effect on the discriminant function when compared to diagnostic test results.

Finally the discriminant function that was created was validated on another dataset, whose classifications were known, to see how well it performed in correctly classifying a new group of students. The validation dataset used contained information on Technology mathematics students in 2009. The discriminant function correctly 
classified $85.2 \%(n=52)$ of the unsuccessful and $58.8 \%(n=130)$ of the successful students and overall correctly classified $64.5 \%(n=182)$ of the dataset. The function was therefore successful in its classification of unsuccessful students in a validation dataset also.

\subsection{Discriminant Analysis Findings: A Summary}

The discriminant function was successful in correctly classifying students who failed mathematics in both the training sample and a validation dataset. Prior mathematical attainment was found to have a larger relative effect on the discriminant function with diagnostic test results helping to refine the prediction of performance. The discriminant function created provides an objective evidence based cut-off point for predicting performance in service mathematics and also provides each student with a probability of failure. The discriminant function has an advantage over the current 'at risk'/not 'at risk' system set out by the diagnostic test as students and lecturers can be clear on the extent to which someone is 'at risk' of failing service mathematics. A student who is 90\% likely to fail service mathematics can now be clearly differentiated from a student who is $50 \%$ likely to fail as opposed to the two of them being labelled 'at risk'. Students are therefore less likely to become complacent as they may have been when labelled 'not at risk' despite them being on the border-line of 'at risk/not at risk'. In addition to this the two dimensional discriminant function provides an objective evidence based cut-off point for predicting performance in service mathematics and therefore advances on the binary classification of the diagnostic test by also providing each student with a probability of failure. This depth of information can enable appropriate mathematics remediation to be put in place specific to students’ needs. 


\section{Non-Standard Students: A Separate Analysis of Technology Students in 2008}

A separate analysis of non-standard students' performances in the diagnostic test and end of term service mathematics examinations in 2008 was also carried out within this research. This analysis details the performance of non-standard students in 2008 only due to the large increase in the proportion of these students in this year and the impact that they were suspected to have had on the overall mathematics performance of the 2008 cohort. The vast majority of non-standard students were not included in the discriminant analysis due to a lack of data related to their prior mathematical attainment. This investigation was carried out with a view to determining how the performance of non-standard students may impact upon the overall performance of the Technology mathematics cohort over time. The majority of the non-standard student cohort is made up of mature students, therefore the majority of non-standard students have not studied mathematics in several years. This is evident in their diagnostic test results. Non-standard students have mean diagnostic test scores (expressed as a percentage of correct answers out of 40 questions) below that of the standard student coming directly from second level education in Ireland. The non-standard students had a mean of $13.0(\mathrm{SD}=8.4)$ compared to the standard students who had a mean of 21.24 $(S D=6.3)$. The difference between these means was found to be statistically significant ( $p<0.001)$. The vast majority of Technological non-standard students, with the exception of a few outliers, are classified as being 'at risk' of failing their end of semester examinations. 117 (42.9\%) of the 273 standard Technology mathematics students who sat the diagnostic test were classified as being 'at risk' of failing Technology mathematics while 23 (76.7\%) of the 30 non-standard Technology mathematics students who sat the diagnostic test were considered to be 'at risk' of 
failing. These findings highlight that non-standard students are mathematically less prepared entering UL than standard students.

The non-standard students improve over time however as can be seen by their performance in the end of semester Technology mathematics examination. The nonstandard students had a mean end of semester performance of $55.8(\mathrm{SD}=29.5)$ while the mean performance of standard students was $53.9(\mathrm{SD}=22.5)$. The difference between these means was not found to be statistically significant however ( $p=0.395$ ). 78 (24.7\%) of the 316 standard Technology students who sat the end of semester examination failed it while 10 (30.3\%) of the 33 non-standard Technology students who sat the end of semester examination failed. The Technology non-standard students therefore performed to a higher standard than would be expected based on their diagnostic test performance. Some possible reasons for non-standard students’ poor performance, which are not all that surprising, in the diagnostic test may be due to being out of practice with formal mathematics [18], a lack of confidence in a formal education setting [46] or simply weak mathematical backgrounds on entry to higher education [47]. Possible suggestions for their improvement in performance over time include: their motivation to succeed [48], their tendency to adapt desirable approaches to learning [49] and their frequent use of available mathematical support services [50].

The discriminant analysis was unable to predict the performance of all students, however the separate analysis of non-standard students' mathematical performance in the diagnostic test and end of term mathematics examination gives some insight into their likely mathematical performances over time. Non-standard students tend to be 'at risk’ at the beginning of the term [47] however desirable learning approaches and engagement with mathematics remediation is likely to have contributed to their improved performance over time $[49,50]$. 


\section{Discussion}

In answer to the first research question: yes one can predict who will fail mathematics in higher education prior to the commencement of the academic term to a reasonable degree of success. This is demonstrated through the findings detailed in section 5.1 which highlighted that the discriminant function correctly classified $68.2 \%$ of the students who were successful and $84.4 \%$ of the students who were unsuccessful in Technology mathematics.

One of the major findings within this research study is the importance of students’ prior mathematical attainment to their success in mathematics in higher education. This finding addresses research question 2 which aimed to determine the best predictors of performance in mathematics in higher education. Despite testing the importance of many variables, the strongest predictor variables of performance in service mathematics in UL were found to be prior mathematical attainment and diagnostic test result. A report on progression in Irish higher education also found that the higher the mathematics attainment in second level education, the more likely it is that students will be present in the second year of their course of study [20].

Internationally mathematical attainment in second level education has also been found to be an effective predictor of performance and progression in higher education. One such study examined determinants of students' tendency to drop-out of higher education as well as the variables which were associated with successful completion [51]. This research found several variables which were associated with retention, for example funding being provided for study, however described their effect on retention as ephemeral when compared to the effect of a student's prior academic attainment, particularly in mathematics. Separate research also found pre-college academic performance (including mathematics performance) to have a statistically significant 
effect on first- year academic performance in higher education $(\mathrm{p}<0.01)$ [19]. A further study detailed the statistically significant association between a student's probability of attaining a bachelor's degree and previous academic attainment as well as involvement with mathematics remediation [52]. Hagedorn et al (1999) conducted a study to determine how students’ background variables influenced their success in mathematics in higher education [53]. In particular, the study examined whether students' enrolled in a remedial mathematics course differed from those enrolled in non-remedial mathematics courses on entry to third level education. Tests of a path analytic model confirmed that students enrolled in non-remedial mathematics courses had a distinct advantage over those enrolled in remedial courses due in part to their statistically significantly higher prior mathematical attainment ( $<<0.0001)$. Liu et al (2008) found that students' prior attainment in second level education had an impact on their ability to problem solve in higher education [54]. Similar outcomes were also documented in studies carried out in the West Indies, the US, Canada and Australia, all of which found prior mathematical attainment to be significant predictors of performance and progression in higher mathematics education [55-58].

The findings addressed in research question 2 along with the international research discussed, which consistently finds prior mathematical attainment to be a significant predictor of performance in mathematics and progression in higher education, cannot be ignored. Students' prior mathematical attainment on entry to higher education initially gives those involved in higher education practice and policy an insight into the probable performances of these students if remediation does not take place. Having this wealth of information therefore leaves institutions in the powerful position of being able to attempt to bridge the mathematical skills gap which a large proportion of beginning undergraduates evidently have before they potentially fail or 
drop-out. Recall from table 2 the large proportion of students considered to be 'at risk' of failing services mathematics according to the diagnostic test; $46.2 \%$ for Technology students in 2008 and $46.0 \%$ for Science students in 2008 . There was also a large proportion of non-standard Technology students (76.7\%) who were considered to be 'at risk' due to their poor diagnostic test performance. The findings detailed in this article therefore provide further evidence for the necessity for higher education institutions to invest in mathematics remediation services. UL have matched the widening of access to higher education and the resulting larger numbers of mathematically underprepared beginning undergraduates with an increase in mathematics remediation services over time.

Despite the lack of support which several critics have for mathematics remediation in higher education [59] the proof that it brings students to the required standards of their respective others is available [40]. A study carried out by Hagedorn et al (1999) examined what variables were significantly related to success in college mathematics for remedial and non-remedial first year college students [53]. This study revealed that non-remedial students had parents with significantly higher education, came from families which had significantly higher incomes and lived in areas and attended schools which were pre-dominantly non-minority (in terms of racial composition) when compared to the remedial students. All of these variables were also found to be statistically significantly related to success in college mathematics ( $\mathrm{p}<$ 0.001). These findings therefore re-emphasise the necessity for remedial mathematical support for beginning undergraduates in an attempt to try to bridge a gap which could be seen to be one of affluence versus lower economic backgrounds [60].

If higher education institutions worldwide wish to continue a system of widening access and education for all they must continue to provide the appropriate 
support services for those growing numbers of students if exit standards are to be maintained [34]. Mathematics remediation is an effective means of coping with "the mismatch between the skills required for successful engagement with scientific and technological courses and the competencies of students enrolling in such course”

The third research question aimed to examine if the current method of determining whether a student is 'at risk' of failing service mathematics in UL (i.e. the diagnostic test) could be improved upon. Both the diagnostic test and the discriminant analysis were reasonably successful in their prediction of students who were unsuccessful in Technology mathematics (the diagnostic test correctly classified $72.9 \%$ of the unsuccessful students in Technology mathematics and discriminant function correctly classified $84.4 \%$ of the unsuccessful students). The discriminant function therefore correctly classified a higher percentage of unsuccessful students and it also correctly classified a slightly higher percentage of students overall than the diagnostic test. The discriminant analysis also has some advantages over the diagnostic test as a method of prediction. Discriminant analysis provides each student with a probability of failure as opposed to just a statement which tells them that they are 'at risk' or that they are not 'at risk'. It provides a student with some insight into the extent to which they may need extra mathematical support, if at all, as opposed to telling them that they do or do not need it. In addition to this, the discriminant function is a classification method which is evidence based as opposed to the diagnostic test classification which is based on a subjective expert opinion only. The prediction analysis carried on in this research therefore did improve somewhat on the current system that was in place (i.e the diagnostic test). The discriminant analysis also helped to refine the cut-off point of the diagnostic test slightly by establishing that a student who receives $18 / 40$ or below is 'at risk' of failing service mathematics as opposed to the 19/40 cut-off point which is 
currently in operation. The examination of students' probabilities of failure in service mathematics on entry to higher education and allowing for appropriate mathematics remediation to be put in for specific cohorts of students is one way of attempting to maintain degree standards in higher education.

The fourth and final research question contained within this research was an examination into what effect (if any) gender had on mathematics attainment in $3^{\text {rd }}$ level education. The effect of gender on mathematics attainment and consequently its strength as a predictor of service mathematics performance was found to be negligible. This finding reiterates what was outlined in a meta-analysis of 100 studies between 1963-1988 in which gender differences in mathematics performance were not found to be significant [61]. A more recent TIMSS (Trends in International Mathematics and Science Study) report further supports this finding suggesting that the trend of negligible differences in mathematics attainment by gender continues to exist [62].

\section{Implications for Policy and Practice}

Prior mathematical attainment was found to be the best predictor of higher education mathematics performance in this study. This was also found to be the case in many other international studies $[53,63]$. This finding will have implications on educational practice and policy in Ireland and elsewhere. It is likely to encourage institutions to examine the level of preparedness of the students due to enter their respective institutions prior to the beginning of the academic year. Such an examination can provide institutions with a warning system regarding the students that will be likely to need mathematical remediation within a particular cohort.

Widening access to higher education worldwide has several follow on effects that are likely to impact on educational policy. One such effect is the documented 
growing numbers of mathematically underprepared beginning undergraduates to higher education [5-6,11]. This highlights the need for higher education authorities to continue to invest in mathematics remediation services. It has been proven to bring students to the required standard and hence assists them to successfully complete their third level education $[53,19,52,64]$ and therefore is a necessity if exit standards are to be maintained in higher education.

The findings reported in this paper also call for those in education policy and practice to facilitate the address of deficiencies in mathematics education at second level. This would at least be likely to have a positive knock on effect on the standard of students entering third level education. One such address has taken place in Ireland with the introduction of a new mathematics curriculum at second level. The new mathematics curriculum aims to turn the focus of second level mathematics teaching towards developing students' understanding of the mathematical concepts by engaging them in problem solving with increased use of contexts and applications encouraging students to relate mathematics to everyday life. Changes were not solely focused on what students learn in mathematics however but also how they learn it and how they will be assessed. The changes to the curriculum were met with appropriate changes to the assessment procedure so that the level of understanding of the students is assessed as well as their subject matter knowledge.

It is anticipated that the follow on benefits from this change in second level mathematics education practices will be seen in third level institutions in Ireland in years to come. Similar moves may be considered internationally to tackle the issues of mathematical deficiencies of students upon entry to third level education at the source of the problem. 
The final implication on policy and practice is concerned with the relationship between diagnostic test performance and service mathematics performance. Although prior mathematical attainment was found to be the most significant predictor of service mathematics performance, diagnostic test performance helped to refine the prediction. The development of a diagnostic test and consequently a database containing students' diagnostic test results over time would therefore be beneficial to institutions worldwide as a means of better understanding the mathematical competency of specific cohorts of students. Such data could also provide some insight into the probable mathematical performances of students for whom prior academic results do not exist (e.g. mature students). Being able to examine students’ performance in a diagnostic test and knowing that performance in a diagnostic test is strongly correlated with end of semester mathematics examination performance would be of huge benefit to institutions with large numbers of non-standards students who enter without any significant prior mathematics qualification.

\section{Conclusion}

The 'Mathematics Problem' is an international phenomenon which has been found to have many contributing factors, one of which is the policy of widening access to higher education. This system of widening access, which is unlikely to change in the near future as all economies are eager to keep their numbers in education high, has lead to a change in the student profile of beginning undergraduates to degree programmes involving mathematics. This new profile of students has brought larger numbers of mathematically underprepared students than ever before to our lecture halls. This study provided an effective way of predicting the mathematical performance of these students, primarily through examination of students’ prior mathematical attainment in second 
level education, with a view to being able to intervene and prevent failure and possibly dropout before it occurs. Prior mathematical attainment was found to be the best predictor of third level mathematics performance and the prior attainment of a large proportion of today's beginning undergraduates indicates that remediation is necessary. Higher education authorities therefore must be prepared to invest in remediation if all students who are accepted as suitable candidates to higher education institutions are to have an equal chance of being successful within their respective degree programmes. If mathematical remediation leads to success for the larger number of students who are predicted to fail mathematics on entry to higher education then it should be considered to be money well spent.

\section{Acknowledgments}

Mathematics Applications Consortium for Science and Industry (MACSI), the National Centre for Excellence in Mathematics and Science Teaching and Learning (NCE-MSTL) and National Academy for Integration of Research, Teaching and Learning (NAIRTL) for funding this research. 